\title{
Aerosol Medications for Treatment of Mucus Clearance Disorders
}

\author{
Bruce K Rubin MEngr MD MBA FAARC
}

\author{
Introduction \\ Composition and Physiologic Role of Mucus \\ Mucoactive Medications \\ Bland Aerosols and Bicarbonate \\ Expectorants \\ Mucolytics \\ Mucokinetic Medications \\ Mucoregulatory Medications \\ Fibrinolytics and Tissue Factor Inhibition \\ Delivery Devices and Importance of Drug-Device Combination \\ Nasal Delivery \\ Order of Aerosol Administration and Administration During Airway \\ Clearance Therapy \\ Conclusions
}

\begin{abstract}
Airway mucus hypersecretion and secretion retention can result from inflammation, irritation, stimulation, or mucus-producing tumors. Secretion clearance can be furthered hampered by ciliary dysfunction and by weakness or restrictive lung disease, leading to an ineffective cough. There are a number of different mucoactive medications that have been used to reduce hypersecretion, make secretions easier to transport, or increase the efficiency of cough or mucus clearance. In this paper, I review the pathophysiology of secretory hyper-responsiveness and mucus hypersecretion and discuss the different aerosol medications that can be used to augment secretion clearance. Key words: mисus; sputum; dornase alfa; acetylcysteine; bicarbonate; mucolytics; expectorants; cystic fibrosis. [Respir Care 2015;60(6):825-832. (C) 2015 Daedalus Enterprises]
\end{abstract}

\section{Introduction}

The airway mucosa responds to acute infection and inflammation with mucus hypersecretion and secretion (phlegm) retention. With chronic exposure, there is mucous (goblet) cell and submucosal gland hyperplasia and

\footnotetext{
Dr Rubin is affiliated with the Department of Pediatrics, Virginia Commonwealth University School of Medicine, and the Children's Hospital of Richmond at Virginia Commonwealth University, Richmond, Virginia.
}

Dr Rubin presented a version of this paper at the 53rd RESPIRATORY CARE Journal Conference, "Aerosol Drug Delivery in Respiratory Care," held June 6-7, 2014, in St Petersburg, Florida. hypertrophy. Products of inflammation (including neutrophil-derived deoxyribonucleic acid [DNA] and filamentous actin), effete cells, bacteria, and cell debris all con-

\footnotetext{
Dr Rubin discloses relationships with Novartis, GlaxoSmithKline, InspiRx, Philips Respironics, Boehringer Ingelheim, the National Institutes of Health, the Cystic Fibrosis Foundation, and the Denny Hamlin Foundation.

Correspondence: Bruce K Rubin MEngr MD MBA FAARC, Department of Pediatrics, Children's Hospital of Richmond at VCU, 1001 East Marshall Street, PO Box 980646, Richmond, VA 23298. E-mail: brubin@vcu.edu.
}

DOI: $10.4187 /$ respcare. 04087 
Table 1. Aerosol Mucoactive Medications

\begin{tabular}{|c|c|c|c|}
\hline Drug & Device & Indication & Notes \\
\hline Albuterol/salbutamol & Nebulizer, pMDI & Asthma, COPD & $\begin{array}{l}\text { No evidence that it improves mucus clearance in patients with lung } \\
\text { disease }\end{array}$ \\
\hline Dornase alfa (Pulmozyme) & Nebulizer (see Table 2) & $\mathrm{CF}$ & Used only for $\mathrm{CF}$ \\
\hline Hyperosmolar $3 \%$ saline & Nebulizer & None & No longer indicated for bronchiolitis \\
\hline Hyperosmolar $7 \%$ saline & Nebulizer & $\mathrm{CF}$ & $\begin{array}{l}\text { No evidence for use other than for } \mathrm{CF} \text {, should not be given via } \\
\text { vibrating mesh nebulizer }\end{array}$ \\
\hline Mannitol (Bronchitol) & DPI & $\mathrm{CF}$, bronchiectasis & Not cleared for use in the United States \\
\hline $\mathrm{N}$-acetylcysteine (Mucomyst) & Nebulizer & None & No evidence for use in any lung disease \\
\hline Anticholinergics & pMDI, DPI & Asthma, COPD & Does not dry secretions \\
\hline \multicolumn{4}{|l|}{$\begin{array}{l}\text { pMDI }=\text { pressurized metered-dose inhaler } \\
\text { DPI }=\text { dry powder inhaler } \\
\text { CF = cystic fibrosis }\end{array}$} \\
\hline
\end{tabular}

tribute to sputum purulence. ${ }^{1}$ Mucus is usually cleared by ciliary movement, and sputum is cleared by cough. Mucoactive medications are intended to increase the ability to expectorate sputum or to decrease mucus hypersecretion, and these medications are classified based on their proposed method of action. Here, I review the use of aerosol mucoactive medications for treating patients with chronic airway diseases associated with poor mucus clearance and with mucus hypersecretion and present the evidence, however limited, of their effectiveness.

\section{Composition and Physiologic Role of Mucus}

Mucus is the normal airway-lining fluid that prevents dehydration of the airway surface, protects the airway from inhaled particles, and aids in clearance of inflammatory mediators, effete cells, debris, inhaled particulates, and pollutants. With inflammation, the secretion is called phlegm. Phlegm contains products of inflammatory cells, including Curschmann's spirals and Charcot-Leyden crystals in patients with respiratory eosinophilia, and DNA and filamentous actin polymers when there are neutrophil extracellular traps or necrosis of inflammatory cells. Phlegm also contains bacteria, debris, and a soup of inflammatory mediators. When phlegm is expectorated, it is called sputum. ${ }^{2}$

In health, mucus consists primarily of water and a polymer of the gel-forming mucins MUC5AC and MUC5B. The mucus layer is secreted by mucous (goblet) cells at the airway surface and in the cartilaginous airways by submucosal glands. The mucus layer rests atop a periciliary fluid layer containing airway surface fluid and tethered mucins, principally MUC1 and MUC4. The mucus layer also contains entrapped debris and antimicrobial peptides. ${ }^{3}$ Cilia transmit force to the mucus without entanglement due, in part, to a surfactant layer separating the airway surface fluid from the mucus gel.
In the distal airways, secretions are pumped by tidal breathing, moving them to airways of larger diameter and lower resistance. In the conducting airways, ciliated cells propel secretions by the metachronal beating of cilia. Mucus clearance depends, in part, on ciliary beat frequency, ciliary power, ciliary coordination, and the surface properties of airway secretions where they touch the cilia or non-ciliated epithelial cell. When there is secretion retention or secretory hyper-responsiveness especially in association with inflammatory damage to the ciliated epithelial surface, secretions in the proximal airways may be cleared by cough. Sputum clearance by cough expectoration depends on cough power, airway dynamics with the equal pressure point moving with air flow, and the properties of secretions, with more viscous and less adhesive secretions being more easily cleared by cough. ${ }^{4}$

\section{Mucoactive Medications}

Medications used to promote mucus clearance have been categorized by their presumed mechanisms of actions (Table 1). ${ }^{5}$ The focus here will be on those delivered by aerosol inhalation.

\section{Bland Aerosols and Bicarbonate}

Although bland aerosols have been administered in an attempt to improve secretion clearance, there is no evidence of their effectiveness, and there is potential risk to adding an airway fluid load in the presence of inflammation. ${ }^{6}$ Although aerosolized or instilled sodium bicarbonate can produce an effective cough, this is presumed to be caused by airway irritation. Bicarbonate is not effective in breaking down secretions or promoting secretion clearance, and because of irritation, I do not recommend the use of aerosolized or instilled sodium bicarbonate for airway hygiene. 


\section{Expectorants}

Secretagogues (expectorants) increase the volume of water and mucus in the airway. ${ }^{7}$ Although medications such as guaifenesin are proposed to be expectorants, data suggest that they are not clinically effective. ${ }^{8}$

Commonly used aerosol expectorants include hyperosmolar 7\% saline and mannitol. Hyperosmolar saline is an effective expectorant in patients with cystic fibrosis (CF). Key studies from Australia showed improvement in lung function but at a cost of bronchospasm, so pretreatment with a bronchodilator is considered important. ${ }^{9}$ Hypertonic saline is thought to act by inducing water and mucus secretion into the airway and by causing an irritant cough. It is inexpensive, but some studies suggest that it is less effective than dornase alfa (Pulmozyme, Genentech, South San Francisco, California). ${ }^{10}$ There are no published data supporting the use of hypertonic saline in combination with dornase alfa or other mucoactive medications.

Mannitol is a sugar that, when inhaled as a dry powder formulation, will draw water and secretions into the airway and act as an expectorant. It has been approved for use in Australia and Europe for the treatment of CF and non-CF bronchiectasis. ${ }^{11}$ Mannitol has a sweet taste, but at the present time, inhalation of a large number of capsules is required for each treatment. Like hypertonic saline, mannitol can cause bronchospasm, so it is recommended that patients be pretreated with an aerosol short-acting bronchodilator such as salbutamol.

Stimulation of the $\mathrm{P} 2 \mathrm{Y}$ purinergic pathway triggers chloride transport through a non-CF transmembrane regulator ion channel. The P2Y2 agonist denufosol has been studied as an expectorant in subjects with $\mathrm{CF}$, but results of the second phase 3 clinical trial (TIGER-2) failed to show improvement in $\mathrm{FEV}_{1}$, so further studies were stopped in 2011.12 Blocking the epithelial sodium channel can also retain water in the airway. The epithelial sodium channel inhibitor amiloride has not been shown to be effective in the treatment of $\mathrm{CF}$, and there is some evidence that its use is associated with deterioration in lung function. ${ }^{13}$

\section{Mucolytics}

Mucolytic medications degrade polymer gels. The classic mucolytics, with $\mathrm{N}$-acetylcysteine being the prototype, have free sulfhydryl groups that hydrolyze disulfide bonds of mucins and other proteins. Peptide mucolytics degrade the copolymer network of DNA and filamentous actin that forms in the course of airway inflammation. ${ }^{7}$ This polymer network is particularly well described in $\mathrm{CF}$, where secretions in the airway contain little intact mucin. ${ }^{14}$ Thus, CF sputum has more in common with pus than with mucus.

Aerosolized $\mathrm{N}$-acetylcysteine has been used for many years as a mucolytic. $\mathrm{N}$-acetylcysteine is inactivated at the airway surface and undergoes first-pass metabolism. Furthermore, it is irritating to the airway, with a pKa of 2.2 and a foul sulfur odor. There are no randomized controlled trials demonstrating a benefit of inhaled $\mathrm{N}$-acetylcysteine or similar mucolytic medications in the treatment of any airway diseases, and therefore, these drugs are not recommended for clinical use. ${ }^{15,16}$

Dornase alfa is a mucolytic medication that targets the DNA polymer network in the CF airway. Dornase has been shown to improve mucus clearance and pulmonary function in subjects with CF. ${ }^{17}$ Aerosolized dornase may also allow better aerosol targeting of other medications to the conducting airway epithelium. Despite extensive study, dornase has not been shown to be effective in diseases other than CF. ${ }^{18}$ Studies on COPD suggest an increased mortality in subjects inhaling dornase, and in subjects with bronchiectasis, there was worsening of lung function and more frequent pulmonary exacerbations during a 24-week clinical trial. ${ }^{19}$ Dornase alfa cannot be recommended for the treatment of any airway disease other than CF.

\section{Mucokinetic Medications}

Mucokinetic medications improve secretion clearance by increasing ciliary beating and/or power, increasing cough air flow, or decreasing adhesion between mucus and cilia. Although medications such as $\beta$-agonist bronchodilators can increase ciliary beat frequency and may increase mucus secretion, they have not been shown to be clinically effective as mucokinetic medications. ${ }^{20}$ Aerosolized surfactant can decrease the adhesive interaction between the ciliary tip and mucus layer when there is breakdown of the normal surfactant layer. ${ }^{21}$

\section{Mucoregulatory Medications}

Mucoregulatory medications decrease stimulated mucus secretion without affecting normal baseline secretion. ${ }^{22} \mathrm{In}-$ haled anticholinergics, including atropine, ipratropium bromide, tiotropium, and glycopyrrolate, do not decrease normal secretion volume or increase the viscosity of secretions, but they do decrease hypersecretion that is triggered by inflammatory activation of muscarinic receptors. ${ }^{23}$ Aerosolized indomethacin has been shown to decrease hypersecretion in subjects with chronic bronchitis, diffuse panbronchiolitis, or bronchiectasis, although the mechanism of action is not clearly known. ${ }^{24}$

\section{Fibrinolytics and Tissue Factor Inhibition}

In patients with airway inflammation and activation of the fibrinogenic pathway, there can be severe airway obstruction by branching mucus casts. This is called plastic bronchitis, and these casts are most commonly seen in 
patients with congenital heart disease and single-ventricle (Fontan) physiology. Plastic bronchitis has also been reported to occur in subjects with sickle cell acute chest syndrome and in some subjects with severe asthma. ${ }^{25}$ There is evidence that inhibiting tissue factor with inhaled heparin may decrease the formation of these casts by decreasing fibrinogenesis. ${ }^{26}$

\section{Delivery Devices and Importance of Drug-Device Combination}

Devices for the administration of aerosol mucoactive drugs target the airway mucus layer, usually in the more proximal airways. However, with severe COPD, CF, and other diseases associated with secretion retention, there is inhomogeneity of air flow, with the most severely affected airways obstructed by secretions. ${ }^{27}$ Unfortunately, this is the part of the airway that needs to be targeted with these medications. There are a number of devices that produce ultrafine particles with a mass median aerodynamic diameter of $<2 \mu \mathrm{m}$ and that limit inspiratory flow to allow greater deposition of these particles in obstructed areas. These devices include the AKITA (Vectura, Chippenham, United Kingdom), AERx (Aradigm, Hayward, California), and I-neb adaptive aerosol delivery system (Philips Healthcare, Andover, Massachusetts). ${ }^{28,29}$ These devices are discussed in greater detail in other articles in this issue of Respiratory CARE.

Many devices have been introduced to augment aerosol medication deposition. Although most of these devices are more expensive than off-the-shelf jet nebulizers, in many cases, the medication being administered is far more costly, making the use of an appropriate drug-device combination not only attractive but now essential for drug approval, safety, and effectiveness. ${ }^{30}$ Table 2 shows many of the drug-device combinations now approved in the United States for mucoactive medications.

\section{Nasal Delivery}

Delivery of mucoactive aerosols targeting the nose and paranasal sinuses is an area of active investigation. Traditionally, water, saline, and occasionally medications have been administered by nasal irrigation using devices such as the Neti Pot, but this has not been shown to be effective in treating sinus disease and can carry risks. ${ }^{32}$

Non-pressurized metered-dose pumps are used to deliver antihistamines, decongestants, and corticosteroids to the nose but not necessarily to the sinuses. Nasal delivery can be enhanced using nebulizers such as the PARI SinuStar (PARI Respiratory Equipment, Midlothian, Virginia), although sinus deposition is still minimal. Data suggest that superimposing pulsatile flow or humming with nasal aerosol will significantly enhance the sinus delivery of medi-
Table 2. Aerosol Drug-Device Combinations

\begin{tabular}{ll}
\hline \multicolumn{1}{c}{ Device } & \multicolumn{1}{c}{ Medication } \\
\hline PARI eFlow & Aztreonam (Cayston) \\
PARI LC Plus & Tobramycin (TOBI, Bramitob) \\
& Colistimethate \\
PARI LC Star & Dornase alfa \\
& Hypertonic saline \\
& Colistimethate \\
Prodose adaptive aerosol delivery & Colistimethate (Promixin) \\
I-neb adaptive aerosol delivery & Colistimethate \\
system & \\
TOBI Podhaler & Tobramycin dry powder \\
Turbospin & Colistimethate dry powder \\
Hudson T Up-draft II & Colistimethate dry powder \\
Marquest Acorn II & Dornase alfa \\
PARI LC Jet & Dornase alfa \\
PARI Baby & Dornase alfa \\
Durable SideStream & Dornase alfa \\
Bronchitol inhaler device & Dornase alfa \\
\hline From Reference 31, with permission. & Mannitol dry powder (Bronchitol) \\
\hline & \\
&
\end{tabular}

cations..$^{33}$ Devices are now commercially available and under development to enhance sinus targeting. These include the PARI Sinus pulsating aerosol system and others. At present, there are no published data demonstrating that nasal administration of mucoactive medications is beneficial, but there are small studies investigating nasal dornase in subjects with CF that suggest an improvement in quality of life with nasal therapy. ${ }^{34}$

\section{Order of Aerosol Administration and Administration During Airway Clearance Therapy}

Because of the large number of aerosol medications given to patients with $\mathrm{CF}$, including bronchodilators, mucoactive medications, inhaled antibiotics, and anti-inflammatory medications, there are guidelines available from different $\mathrm{CF}$ centers that recommend a specific order of administration of medications. ${ }^{35}$ However, not only are these guidelines lacking empiric data from randomized controlled trials, many of these guidelines recommend that aerosol medications be given in a sequence that is quite different from other guidelines. Thus, the order of administration of $\mathrm{CF}$ aerosol medications in association with airway clearance therapy is more of a belief system than science. For example, small studies have not shown any difference in effectiveness when dornase was given before, during, or after other aerosol therapy. ${ }^{36}$ For patients using airway clearance therapy with high-frequency chestwall compression, there is no contraindication to receiving 


\section{Muconctive Aerosols}

inhaled mucoactive therapy simultaneously. Although current data cannot support any specific order of aerosol administration, a general principal is that fewer medications result in better adherence to therapy, and good adherence probably trumps the order of administration.

\section{Conclusions}

There are a variety of different medications that have been proposed for the treatment of airway mucus secretion. Work is in progress to develop guidelines for the use of these drugs and to find effective aerosol therapy for chronic rinosinusitis.

\section{REFERENCES}

1. Kater A, Henke MO, Rubin BK. The role of DNA and actin polymers on the polymer structure and rheology of cystic fibrosis sputum and depolymerization by gelsolin or thymosin beta 4 . Ann NY Acad Sci 2007;1112:140-153.

2. Rubin BK. Mucus, phlegm, and sputum in cystic fibrosis. Respir Care 2009;54(6):726-732; discussion 732.

3. Voynow JA, Rubin BK. Mucus, mucins, and sputum. Chest 2009; 135(2):505-512.

4. Rubin BK. The role of mucus in cough research. Lung 2010;188(Suppl 1):S69-S72.

5. Rubin BK. The pharmacologic approach to airway clearance: mucoactive medications. Paediatr Respir Rev 2006;7(Suppl 1):S215S219.

6. Kallstrom TJ, AARC. Clinical practice guideline. Bland aerosol administration-2003 revision and update. Respir Care 2003;48(5):529533.

7. Rubin BK. Mucolytics, expectorants, and mucokinetic medications. Respir Care 2007;52(7):859-865

8. Hoffer-Schaefer A, Rozycki HJ, Yopp MA, Rubin BK. Guaifenesin has no effect on sputum volume or sputum properties in adolescents and adults with an acute respiratory tract infections. Respir Care 2014:59(5):631-636.

9. Elkins MR, Robinson M, Rose BR, Harbour C, Moriarty CP, Marks $\mathrm{GB}$, et al. A controlled trial of long-term inhaled hypertonic saline in patients with cystic fibrosis. N Engl J Med 2006;354(3):229-240.

10. Suri R, Grieve R, Normand C, Metcalfe C, Thompson S, Wallis C, Bush A. Effects of hypertonic saline, alternate day and daily rhDNase on healthcare use, costs and outcomes in children with cystic fibrosis. Thorax 2002;57(10):841-846.

11. Daviskas E, Rubin BK. Effect of inhaled dry powder mannitol on mucus and its clearance. Expert Rev Respir Med 2013;7(1):65-75.

12. Moss RB. Pitfalls of drug development: lessons learned from trials of denufosol in cystic fibrosis. J Pediatr 2013;162(4):676-680.

13. Burrows EF, Southern KW, Noone PG. Sodium channel blockers for cystic fibrosis. Cochrane Database Syst Rev 2014;4:CD005087.

14. Henke MO, Renner A, Huber RM, Seeds MC, Rubin BK. MUC5AC and MUC5B mucins are decreased in cystic fibrosis airway secretions. Am J Respir Cell Mol Biol 2004;31(1):86-91.

15. Black PN, Morgan-Day A, McMillan TE, Poole PJ, Young RP. Randomised, controlled trial of $\mathrm{N}$-acetylcysteine for treatment of acute exacerbations of chronic obstructive pulmonary disease. BMC Pulmon Med 2004;4:13.
16. Tam J, Nash EF, Ratjen F, Tullis E, Stephenson A. Nebulized and oral thiol derivatives for pulmonary disease in cystic fibrosis. Cochrane Database Syst Rev 2013;7:CD007168

17. Laube BL, Auci RM, Shields DE, Christiansen DH, Lucas MK, Fuchs HJ, Rosenstein BJ. Effect of rhDNase on airflow obstruction and mucociliary clearance in cystic fibrosis. Am J Respir Crit Care Med 1996;153(2):752-760

18. Rubin BK. Who will benefit from DNase? Pediatr Pulmonol 1999; 27(1):3-4

19. O'Donnell AE, Barker AF, Ilowite JS, Fick RB. Treatment of idiopathic bronchiectasis with aerosolized recombinant human DNase I. rhDNase Study Group. Chest 1998;113(5):1329-1334.

20. O'Riordan TG, Mao W, Palmer LB, Chen JJ. Assessing the effects of racemic and single enantiomer albuterol on airway secretions in long-term intubated patients. Chest 2006;129(1):124-132.

21. Anzueto A, Jubran A, Ohar JA, Piquette CA, Rennard SI, Colice G, et al. Effects of aerosolized surfactant in patients with stable chronic bronchitis: a prospective randomized controlled trial. JAMA 1997; 278(17):1426-1431.

22. Rubin BK, Priftis KN, Schmidt HJ, Henke MO. Secretory hyperresponsiveness and mucus hypersecretion. Chest 2014;146(2):496-507.

23. Bateman ED, Rennard S, Barnes PJ, Dicpinigaitis PV, Gosens R, Gross NJ, et al. Alternative mechanisms for tiotropium. Pulm Pharmacol Ther 2009;22(6):533-542

24. Tamaoki J, Chiyotani A, Kobayashi K, Sakai N, Kanemura T, Takizawa T. Effect of indomethacin on bronchorrhea in patients with chronic bronchitis, diffuse panbronchiolitis, or bronchiectasis. Am Rev Respir Dis 1992;145(3):548-552.

25. Madsen P, Shah SA, Rubin BK. Plastic bronchitis: new insights and a classification scheme. Paediatr Respir Rev 2005;6(4):292-300.

26. Eason DE, Cox K, Moskowitz WB. Aerosolised heparin in the treatment of Fontan-related plastic bronchitis. Cardiol Young 2014;24(1): 140-142.

27. Laube BL, Links JM, LaFrance ND, Wagner HN Jr, Rosenstein BJ. Homogeneity of bronchopulmonary distribution of ${ }^{99} \mathrm{mTc}$ aerosol in normal subjects and in cystic fibrosis patients. Chest 1989;95(4): 822-830.

28. Rubin BK. Pediatric aerosol therapy: new devices and new drugs. Respir Care 2011;56(9):1411-1421; discussion 1421-1423.

29. Rubin BK, Williams RW. Emerging aerosol drug delivery strategies: from bench to clinic. Adv Drug Deliv Rev 2014;75:141-148.

30. Rubin BK. Air and soul: the science and application of aerosol therapy. Respir Care 2010;55(7):911-921.

31. Williams R, Rubin BK. Aerosol therapy for the therapy of CF. In: Bush A, Bilton D, Hodson, M. Hodson and Geddes' cystic fibrosis, 4th edition. London: Taylor \& Francis; 2015:279-297.

32. Kassel JC, King D, Spurling GK. Saline nasal irrigation for acute upper respiratory tract infections. Cochrane Database Syst Rev 2010; (3):CD006821

33. Laube BL. Devices for aerosol delivery to treat sinusitis. J Aerosol Med 2007;20(Suppl 1):S5-S17; discussion S17-S18

34. Mainz JG, Schien C, Schiller I, Schädlich K, Koitschev A, Koitschev $\mathrm{C}$, et al. Sinonasal inhalation of dornase alfa administered by vibrating aerosol to cystic fibrosis patients: a double-blind placebo-controlled cross-over trial. J Cyst Fibros 2014;13(4):461-470.

35. Flume PA, Robinson KA, O'Sullivan BP, Finder JD, Vender RL, Willey-Courand DB, et al. Cystic fibrosis pulmonary guidelines: airway clearance therapies. Respir Care 2009;54(4):522-537.

36. Dentice R, Elkins M. Timing of dornase alfa inhalation for cystic fibrosis. Cochrane Database Syst Rev 2013;6:CD007923. 


\section{Discussion}

DiBlasi: Bruce, that was an amazing presentation, as usual. There seems to be a proliferation of new devices that are being introduced to the market, and a number of these are highfrequency devices that patients can breathe spontaneously through while receiving a treatment. Do you think there's any potential for these devices to provide some of that drug farther down in the lungs, especially in those airways that are obstructed? It seems like the Acapella (Smiths Medical, Ashford, United Kingdom) and Aerobika (Monaghan Medical, Plattsburgh, New York) are very attractive options for this, but there aren't a lot of data to support using this combined therapy in our patient population. I've always been under the impression that you give the bronchodilator and then do CPT (chest percussive therapy) or airway clearance next, but maybe it's the other way around because there are conflicting reports where people give the bronchodilator first and then do CPT, or they combine the therapy. What is your feeling about providing bronchodilators and other drugs using these devices, which essentially percuss the airway?

Rubin: Great question, Rob. First, I'll speak to the order of delivery; this is more of a religion then a science, with each clinician having his/her own way of doing this. For example, first you open the airways with the bronchodilator, then you give the mucolytic and be sure that it gets down there, then you do airway clearance to clear it out, then you give them inhaled antibiotics so it can stay down there ... but there are no data suggesting that one order is better than any other. The idea of giving these simultaneously is attractive primarily because it decreases the amount of time for these therapies. There was one unpublished study done by Bonnie Das Gupta some 20 years ago looking at radioaerosol deposition in subjects with $\mathrm{CF}$ who were using aerosol either before or after the HFCWC (highfrequency chest-wall compression) vest that suggested better aerosol deposition with the vest. To my knowledge, this has never been published or replicated clinically. If somebody could show us data that this improved lung function or deposition or something clinically meaningful, I think it would be great. Until then, we are telling patients to do whatever is most comfortable, so they'll do it consistently.

Berlinski: I want to address that question as well. There were actually 2 studies published this year: one in vivo study that Jim Fink coauthored $^{1}$ and one in vitro study from my lab. ${ }^{2}$ We found when the vibrating PEP (positive expiratory pressure) device (Acapella) was concomitantly used with a nebulizer, the aerosol experienced a size selection when it traveled through the housing of the device. In fact, the particle size decreased from 4 to $1.2 \mu \mathrm{m}$. There was also a decrease in the amount of drug, with a loss of $70-80 \%$. I was very pleased to find that it was also the case in an in vivo study in which the authors put the nebulizer in the back of the Acapella, and they found a 70\% decrease in the amount of intrapulmonary deposition measured with radiolabeling. The conclusion is that it should not be used as concomitant delivery for that type of device. In my in vitro study, I also looked at a PARI device that doesn't interfere with the flow, and it did not show any changes in particle size at all. ${ }^{2}$ We're not sure what happens with intrapulmonary deposition, but at least from the particlesize characterization, it doesn't interfere with the production of the aerosol.

* Suggett: Just a comment on that point because it's the Acapella device that has the more torturous inhalation flow path; the PARI PEP obviously doesn't, and neither does the Aerobika OPEP (oscillating PEP) device. I think when you look at the in vitro deposition through the Aerobika device for nebulized delivery on inhalation compared with the Acapella, the data we produced ${ }^{3}$ actually married up with the data you produced in vitro. So it does depend on the pathway. If the pathway for nebulizer delivery via the PEP/OPEP device is not altered appreciably, the in vitro deposition doesn't differ, although it should be proved clinically. Another question is the downside for combining, say, hypertonic saline nebulized delivery via a PEP/OPEP device if you know you can deliver the same amount and you can shorten the treatment time for a CF patient. Is there a downside to that?

Rubin: The only downside is not having the data. I think most clinicians would agree with you, but only if there were clinical data to support what you are saying.

$\dagger$ Fink: So, in our study that Ariel (Berlinski) refers to, we took a look at placing the nebulizer where the manufacturer said to put it, ${ }^{1}$ and then we put it between the device and mouthpiece, and we got better deposition. That was true also when we looked at the Hill-Rom device, the MetaNeb. It's the first device I've ever measured with virtually no aerosol delivered during use, but placing the nebulizer between the manifold and mouthpiece gave good aerosol delivery. Core to the question, I think, is that most of this isn't due to better response to bronchodilators or whatever drug because of the oscillation; it's based on 20-yearold data showing there's an improved response to bronchodilators when given with PEP. And these devices create PEP as well as oscillation.

\$ MacIntyre: I'm going to switch gears from devices. I'd like to go back to my patient I described earlier when Marcos (Restrepo) was up there. So the patient is stuck on the ventilator. This is a real case; I saw him yesterday. He is doing better except for the fact that he's got these secretions that make everybody scared to remove the 
tube. Marcos talked me out of putting an aerosolized antibiotic in there, you talked me out of putting N-acetylcysteine down there, and you've talked me out of putting dornase alfa down there ... it sounds like maybe an anticholinergic might be useful under these circumstances? Maybe surfactant?

\section{Rubin: Maybe.}

$\$$ MacIntyre: Should I grab some Exosurf and squirt it down there Monday morning when I'm back in the unit?

Rubin: I no longer have a North Carolina license, so I'll defer about Monday. "Maybe" means we have some small studies that have been done once; there are no replicated studies. They were carried out with a specific nebulizer with a specific surfactant. So I wouldn't just squirt it down there. I'd love to see people do that study. Doug (Willson) and I have been toying with ideas like that, but you know as well as I do that you can't extrapolate good clinical practice.

$\$$ MacIntyre: I'm just trying to figure out what I'm going to do on Monday morning with this guy.

\section{Rubin: Transfer to UNC Chapel} Hill?

Hill: Thank you for that great talk. The question I have is related to $\mathrm{N}$-acetylcysteine. I don't think we need an RCT (randomized controlled trial) to demonstrate that it's a great mucolytic ex vivo. You know, during bronchoscopy, you put some $\mathrm{N}$-acetylcysteine solution on mucus in a dish, and it dissolves like magic. Actually—some may shudder at this, but perhaps others use it-mucus plugs disappear and are much easier to remove by suction if you wash them with 5 to $10 \mathrm{~mL}$ of a $10 \%$ solution of $\mathrm{N}$-acetylcysteine. I make it by mixing a vial of $20 \% \mathrm{~N}$-acetylcysteine with equal parts saline. Patients seem to tolerate this very well. Obviously, this reduces mucus viscosity. Yet, as you pointed out, the stud- ies show no benefit when it's used as an aerosol. Part of the problem is that we may not be dealing with actual mucus but rather purulent secretions that might not dissolve as easily. Also, in patients with asthma, it might have irritant effects, too. Are we delivering it the wrong way, is there something wrong with our methodology, or is there just nothing to it once we try to aerosolize it into the lungs?

Rubin: Again, I can only speculate, but if you have a bronchoscope and a suction channel and you're liquefying it and pulling it straight back, then you're doing a world of good. If you're liquefying it and not sucking it out immediately and the patient doesn't have a great cough because he/she's sick as sin, it's just going to go down there and pool like stagnant water at the bottom of a pool that's been abandoned. This will do more harm than good. The data suggest that it is no better than placebo. It could be due to any one of a number of reasons; my guess is that thinning secretions just isn't all that it's cracked up to be in terms of coughing things out.

$\dagger$ Fink: Another issue is that just like antibiotics and so many drugs that we give to the lungs for effect, it isn't just that you nebulized it, but it's the concentration that actually reaches where you want it to go. There's a difference between pouring $3 \mathrm{cc}$ through your scope onto a glob of mucus and taking $3 \mathrm{cc}$ and getting $3 \%$ of it with a jet nebulizer spread out in the entire 70 square meters of the lung. You're probably not getting a high enough target dose or concentration to get the effect.

Hill: Do you know what it does to ciliary function?

Rubin: Because it has a low $\mathrm{pH}, \mathrm{I}$ would think it would initially increase it. Anything that irritates the cilia, be it allergens or other irritants, will initially increase ciliary beat frequency and then will eventually slow it. So I would think there would be an initial increase, but I don't know for sure.

Willson: Bruce, another comment or approach to trying to clear out secretions down the airways-but not mine-is dilute bicarbonate. Would you comment on that?

Rubin: Okay. You know from working with John Hunt that the airway is acidified and that increasing $\mathrm{pH}$ within the airway to normalize it will decrease inflammation, perhaps. They're using bicarbonate as a mucolytic, and it's pretty darn irritating. I don't think there are any data to support that, and I think it's potentially harmful, so I probably would not use it. In the ICU, folks often shoot it down as a liquid into the airway. Parenthetically, there are also people who do suctioning all the way down to the alveolus, leading to all kinds of granulomas and things like that. They figure that if you're not getting a good chunk of liver with each suction, you've not gone far enough. There are even people who will take saline and squirt it down to loosen up secretions, but first bag it! And I'm thinking, you've loosened everything, now you're pushing it down as deep as it will go into the airway, and then you want to try and get it out? So there are many strange things done "neath the midnight sun.

DiBlasi: What's your stance on the use of perfluorocarbons for mucus removal? It seems to be the buzz in Europe right now.

Rubin: We did earlier work with perflubron when it was still being studied as a means of liquid ventilation, and we got involved because people were getting all sorts of garbage up with its use. We saw similar results when surfactant was instilled. Indeed, perfluorocarbons have very low surface tension. The surface tension of perflubron is $10 \mathrm{dyne} / \mathrm{cm}$, and like surfactant, it may help unstick and remove secretions from the airways. I like the concept, and I think it would be great to study. I haven't seen any 
publications showing that it's effective, but I think it would be well worth looking at.

Hess: I'd like to get back to Neil's patient. My question for you, Neil, is rather than to try to affect the volume of secretions that are being produced if the patient has a good cough, why not just take the tube out and let the patient cough out the secretions? Or use a cough assist machine to clear the secretions and not get hung up on the fact that there are a lot of secretions in the airway?

+ MacIntyre: Well, Dean, you and I were both on the guidelines committee, and we wrote that if you have to suction more than every hour, you ought to leave the tube in.

Hess: Well, after 10 years, sometimes it's not good to keep listening to your old lines.

* Jason A Suggett PhD MBA, Monaghan Medical.

$\dagger$ James B Fink PhD RRT FAARC, James B Fink LLC, San Mateo, California, and Division of Respiratory Therapy, Georgia State University, Atlanta, Georgia, representing Aerogen. $\ddagger$ Neil R MacIntyre MD FAARC, Division of Pulmonary and Critical Care Medicine, Duke University, Durham, North Carolina, representing InspiRx.

\section{REFERENCES}

1. Mesquita FO, Galindo-Filho VC, Neto JL, Galvão AM, Brandão SC, Fink JB, Dornelas-de-Andrade A. Scintigraphic assessment of radio-aerosol pulmonary deposition with the Acapella positive expiratory pressure device and various nebulizer configurations. Respir Care 2014;59(3):328333.

2. Berlinski A. In vitro evaluation of positive expiratory pressure devices attached to nebulizers. Respir Care 2014;59(2): 216-222.

3. Suggett J, Mitchell J, Avvakoumova V, Ali $\mathrm{R}$, Schneider $\mathrm{H}$. Combining inhalation by a breath-actuated nebulizer (BAN) with exhalation with oscillating positive expiratory pressure device (OPEP) offers potential for simultaneous therapy Eur Respir J 2013; 42(Suppl 57):P2115.

This article is approved for Continuing Respiratory Care Education credit. For information and to obtain your CRCE

(free to AARC members) visit 